\title{
Performance analysis of cation and anion exchangers in water treatment plant: an industrial case study
}

\author{
Naveed Ramzan', Nadeem Feroze ${ }^{1}$, Mohsin Kazmi ${ }^{1, *}$, Muhammad Arsalan Ashraf ${ }^{2}$, Sajid Hasan ${ }^{3}$ \\ ${ }^{1}$ Department of Chemical Engineering, University of Engineering and Technology Lahore, Pakistan \\ ${ }^{2}$ Process Engineer, Dawood Hercules Chemicals Limited, Lahore, Pakistan \\ ${ }^{3}$ Technical Manager, Dawood Hercules Chemicals Limited, Lahore, Pakistan \\ "Corresponding author: e-mail: engr.smalikazmi@gmail.com
}

\begin{abstract}
Performance of cation and anion exchangers was evaluated by carrying out breakthrough analyses of $\mathrm{pH}$, conductivity, free mineral acid (FMA) and various dissolved solids for an industrial water treatment plant of $700 \mathrm{gpm}$ capacity. The breakthrough curves showed no leakage of calcium, magnesium and chloride throughout the operating period of the train, however, they indicated the early leakage of sodium, potassium, sulphate and silica. The operating/breakthrough capacity, total capacity and degree of column utilization were determined. The column utilization was found to be $67.85 \%, 38.93 \%$ and $16.78 \%$ against the design values of $90 \%, 85 \%$ and $85 \%$ for cation, primary and secondary anion exchangers respectively. The operating time of the water treatment train was significantly increased by achieving adequate capacity utilization of secondary anion exchanger. The low capacity utilization of secondary anion resin due to early silica slippage, has been discussed in the paper.
\end{abstract}

Keywords: breakthrough curves, degree of column utilization, ion exchange, water treatment.

\section{INTRODUCTION}

Ion exchange is the reversible stoichiometric exchange of ions between a resin particle and the surrounding liquid without a significant change in the particle structure $^{1}$. Earlier, some operating conditions were considered harmful to the resin beads while on these conditions resins perform effectively and economically ${ }^{2}$. It is often unappreciated that the ion exchange systems are unique in the sense that they achieve steady state almost instantaneously and require no thermal energy ${ }^{3}$.

Generally a packed bed of ion-exchange resin beads is used for exchange reaction. Source water is passed through the bed in a down flow or up flow mode until the resin is exhausted (as evidenced by the appearance of the unwanted contaminant at an unacceptable concentration in the effluent). The exhausted bed is regenerated using an excess of the presaturant ion. Ideally, no permanent structural change takes place during the exhaustion/ regeneration cycle ${ }^{4}$. Problems in regeneration may also be due to insufficient contact time and or resin fouling5. Two basic designs are available for the regeneration of ion exchange columns viz, countercurrent or concurrent regeneration. The co-current regeneration columns are cheaper than the counter current. However, the utilization of the regenerant is less efficient in the co current scheme than the counter current and presents higher leakage of ion to be removed ${ }^{4}$.

The time to breakthrough is an important parameter in an ion-exchange column, because it measures the total exchange that may occur before the exchanging ion begins to be lost to the exit solution ${ }^{6}$. The bed volumes throughput (BV) to a given breakthrough is directly dependent on the resin capacity used ${ }^{7}$. The operating efficiency depends on several factors, including the choice of resin, regeneration level, flow rate during the service cycle, quality level used to determine the start and the end of the service cycle, and the method of regeneration. As compared to the co-current regeneration, the counter current regeneration is beneficial to produce very high quality water by minimizing ionic species leakage. This is due to increase in the regenerant contact efficiency and full regeneration of the resin bottom bed ${ }^{8}$.

Column performance studies for the fixed-bed columns are concerned with the concentration history of the column effluent that is, with the variation in concentration as a function of time or of the volume of the effluent. A steep breakthrough curve makes it possible to utilize a large fraction of the theoretical capacity of the resin'. Capacity checks indicate an appreciable difference between the total capacity of the resin and the capacity calculated ${ }^{\mathbf{1 0}}$.

The focus of this work is the performance analysis of cation and anion exchangers at water treatment plant by plotting the breakthrough curves of ions being exchanged, by evaluating column utilizations during operation, by analyzing available operating capacities after plant site regeneration and in laboratory regeneration by using excess regenerating chemicals and to determine the probable causes of decrease in operating column utilization.

\section{THEORETICAL FUNDAMENTALS}

Ion exchangers are insoluble solid materials which carry exchangeable cations and anions. These ions can be exchanged for a stoichiometrically equivalent amount of other ion of same sign when ion exchanger is in contact with an electrolyte solution. Carriers of exchangeable cations are called cations and carriers of exchangeable anions are called anion exchangers ${ }^{11}$.

The operating capacity is determined from the value of the total exchangeable ions in the column at the break-through end point ${ }^{12}$. The overall or total capacity is given by the volume capacity of the ion exchanger and the size of the bed. The degree of column utilization is the fraction of ion exchange material which is effective that is obviously given by the ratio of the breakthrough or operating and the overall capacities ${ }^{11}$.

Anion resins are susceptible to fouling by organics in makeup water. The fouling produces increasingly ir- 
reversible loss of capacity, since very few organics are eluted during regeneration. Most surface organics are hydrophobic, as are many strong base anions; as a result, adsorptive forces are strong, and irreversible fouling is likely. Soluble organics, characterized by relatively high molecular weight, can readily block the exchange sites. This results in premature poor effluent quality with respect to silica, conductivity and $\mathrm{pH}$. The organic foulants can degrade the exchange capacity by blocking the exchange sites which reduces the rate of diffusion of inorganic ions to the exchange sites ${ }^{13}$.

A minimum contact time must be allowed in order to enable the regenerant solution to act efficiently upon the resin and ensure that the ions fixed by the latter are completely eluted. Hardness leakage occurs rarely suggests poor performance on the part of cation resin. If the cation resin is incompletely regenerated, the decationized water will contain some sodium chloride, which will react with strong base functional groups found in any weak base resin. This result is a salt splitting reaction which releases caustic soda. The caustic soda released in this way will act as a regenerant and cause leakage of silica ions.

After a certain period of use, strong base anion exchange resin may contain a large amount of silica, if the regeneration process is inadequate in terms of the quantity of caustic soda, temperature or operating conditions. The silica may polymerize within the pores of resin, and the ability of the system to remove it may thus be reduced ${ }^{14}$.

\section{MATERIALS AND METHODS}

Table 1 shows the details of the resins used. Shimadzu - 6800 atomic absorption spectrophotometer was used to analyze calcium, magnesium, sodium and potassium. Spectrophotometer was used to analyze chloride, sulfate and silica. The $\mathrm{pH}$ meter was used to analyze $\mathrm{pH}$, the conductivity meter was used to analyze conductivity.

\section{Experimental set up and description}

The water treatment plant of $700 \mathrm{gpm}$ at Dawood Hercules Limited Lahore, Pakistan has been taken as a case study (see Fig. 1 for process flow diagram). Raw feed water pumped to the demineralization plant. A pressure control valve PCV-1 is used to maintain the inlet pressure of $80 \mathrm{psig}$. During normal operation, the service inlet valve S1 and the service outlet valve S2 of cation exchanger are in open condition.

The backwash inlet valve B1, the backwash outlet valve $\mathrm{B} 2$, the acid injection valve A1 and the waste outlet valve $\mathrm{W} 1$ are to be closed. The pressure indicators are installed at the inlet and outlet of the cation exchangers.
Water flows from cation exchanger to the degasifier through valve S3. Water is showered over rasching rings against the flow of air by the blower and moves down in the storage of the degasifier. The water is pumped from the degasifier to the primary anion exchanger by two pumps P1 \& P2. Pressure control valve PCV-2 is used to maintain the pressure at the inlet of the primary anion exchanger.

The service inlet S4 and the service outlet S5 valves of primary anion exchanger are in open position. The backwash inlet B3, the backwash outlet B4, the caustic injection $\mathrm{C} 1$ and waste outlet $\mathrm{W} 2$ valves are to be closed.

The water from primary anion exchanger goes to the secondary anion exchanger. The service inlet S6 and service outlet $\mathrm{S} 7$ valves of secondary anion exchanger are in open position. The backwash inlet B5, the backwash outlet B6, the caustic injection $\mathrm{C} 2$ and the waste outlet W3 valves are to be closed.

The filtered water to be treated is supplied and passes into a manifold, entering the cation exchangers at the top, passing down the flow through the resin beds. The vessels operate flooded so the incoming water displaces the contained water downward through the beds. The cation exchanger contains strong acid cation exchange resin C-255 manufactured by Duolite having the total ion exchange capacity of $2.1 \mathrm{eq} / \mathrm{lit}$. As the water flows downward through the beds of the cation exchangers, the metallic cations are taken from the water and retained by the bed exchange material. In doing so, an equivalent amount of hydrogen ions are exchanged to the anion radicals. When regenerated, the acid used removes the accumulated metallic cations and restores the hydrogen to the exchanger.

The purpose of the primary anion is to remove chloride and sulfate, from the degasifier effluent water. The water is pumped from the cation effluent pump to the three primary anion exchangers where it enters the vessel from the top and passes through the weak base anion exchange resin. After exchanging hydroxyl ions attached to the resin with that of strong acids it passes from the outlet of exchanger and moves towards secondary anion exchangers. Purolite A100 is a polystyrene based strong base anion resin. The functional group of A100 is tertiary amine. A100 has high operating capacity 1.3 eq/lit to remove strong acids from the decationized water that passed from strong acid cation resin and degasifier. It removes efficiently the organic species present in water and has high elution efficiency of organic species during regeneration.

Strong base anion resin has the ability to remove weak acids and strong acids from the water. The primary function of secondary anion exchanger is to remove weak

Table 1. Details of different ion exchangers used in the study

\begin{tabular}{|c|c|c|c|}
\hline Resin Properties & Cation Exchangers & Primary Anion Exchangers & Secondary Anion Exchangers \\
\hline Description & $\begin{array}{l}10 \% \text { Cross linked Strong Acid Cation } \\
\text { Resin }\end{array}$ & Weak Base Tertiary Amine & $\begin{array}{l}\text { Styrene Divinylbenzene } \\
\text { Copolymer }\end{array}$ \\
\hline Manufacturer & Duolite & Purolite & Amberlite \\
\hline Model number & C-255 & A-100 & IRA $402 \mathrm{Cl}$ \\
\hline Functional Group & $\mathrm{SO}_{3} \mathrm{H}$ & Tertiary Amine & $-\mathrm{N}^{+}\left(\mathrm{CH}_{3}\right)_{3}$ \\
\hline Ionic form as shipped & Sodium & Chloride & Chloride \\
\hline $\begin{array}{l}\text { Total lon exchange } \\
\text { Capacity }\end{array}$ & $\geq 2.1 \mathrm{eq} / \mathrm{L}$ ( $\mathrm{Na}$ form) & $\begin{array}{l}1.3 \mathrm{eq} / \mathrm{l}(28.4 \mathrm{Kgr} / \mathrm{ft} 3) \text { (Free Base } \\
\text { form) }\end{array}$ & $\geq 1.2$ eq/lit $(\mathrm{Cl}$ form $)$ \\
\hline
\end{tabular}




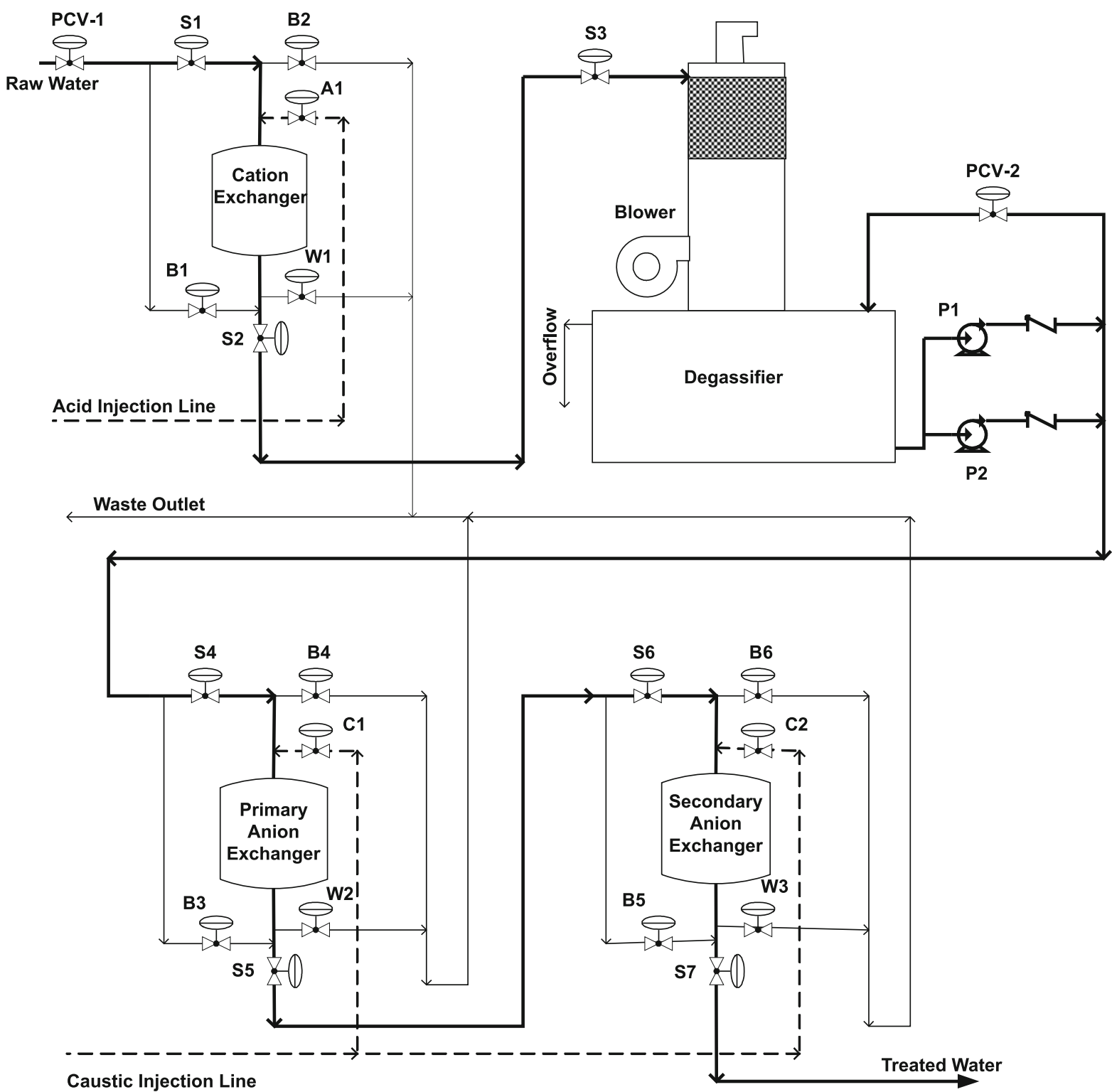

Figure 1. The experimental setup for water demineralization acids i.e. carbonic acids and silicic acids. In addition to this, due to its property it removes strong acids that slip down from primary anion exchangers as well. The secondary anions remove silica and bicarbonates from the degasifier effluent water. Silica is removed effectively to $0.05 \mathrm{ppm}$ and dissolved mineral content to $6 \mathrm{ppm}$. Amberlite IRA $402 \mathrm{Cl}$ is a premium grade strongly base anion resin with a clear gel structure having the total ion exchange capacity of $1.3 \mathrm{eq} / \mathrm{lit}$. It is based on the cross linked polystyrene and has a very high bead integrity, good regeneration efficiency and excellent rinse performance.

\section{RESULTS AND DISCUSSION}

The water content in the inlet and outlet streams of the water treatment plant was monitored. The typical breakthrough curves of calcium, magnesium, sodium, potassium, chloride, sulfate and silica are presented in figure 2-5. It was observed that for calcium and magnesium there is no breakthrough (not shown). In the primary anion exchanger, there is no breakthrough of chloride (not shown) while for sulfate the breakthrough appears at the start of the train and increases with the passage of time. In secondary anion exchanger, the

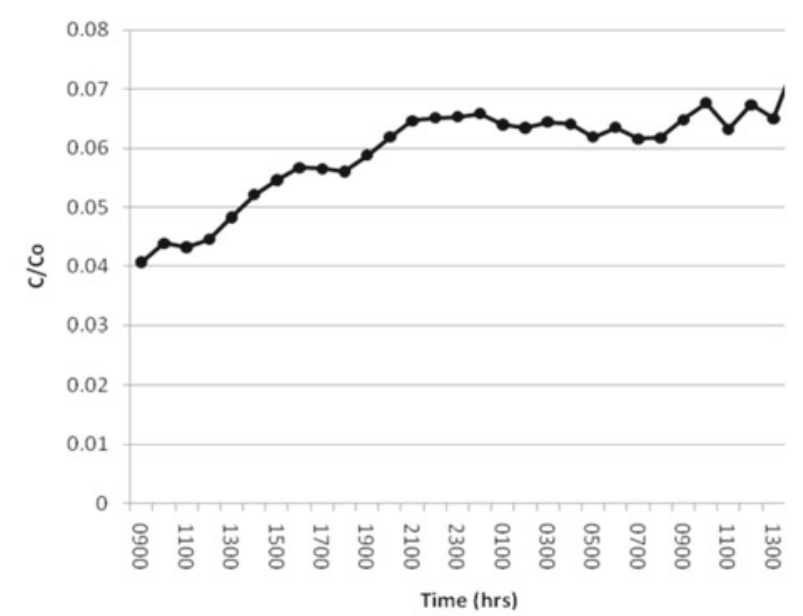

Figure 2. Breakthrough curve of sodium

silica breakthrough occurs at the start of the train and increases with the passage of time and the train taken out of service as silica concentration reaches $0.049 \mathrm{mg} / \mathrm{lit}$.

The existing system uses the co-current regeneration method as the regenerant and the water flow in same direction from the upward to downward direction in an ion exchanger. In this arrangement, the lower bed cannot be fully regenerated, which is attributed to the 


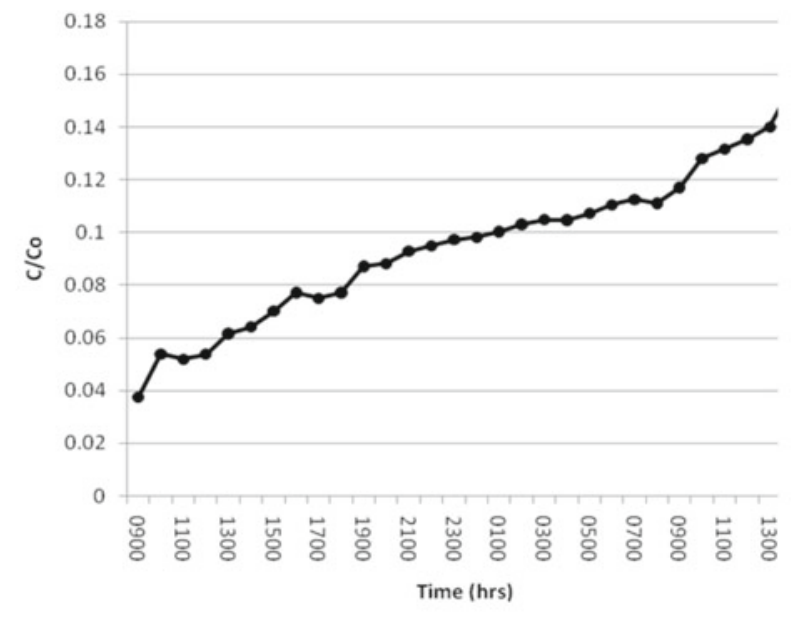

Figure 3. Breakthrough curve of potassium

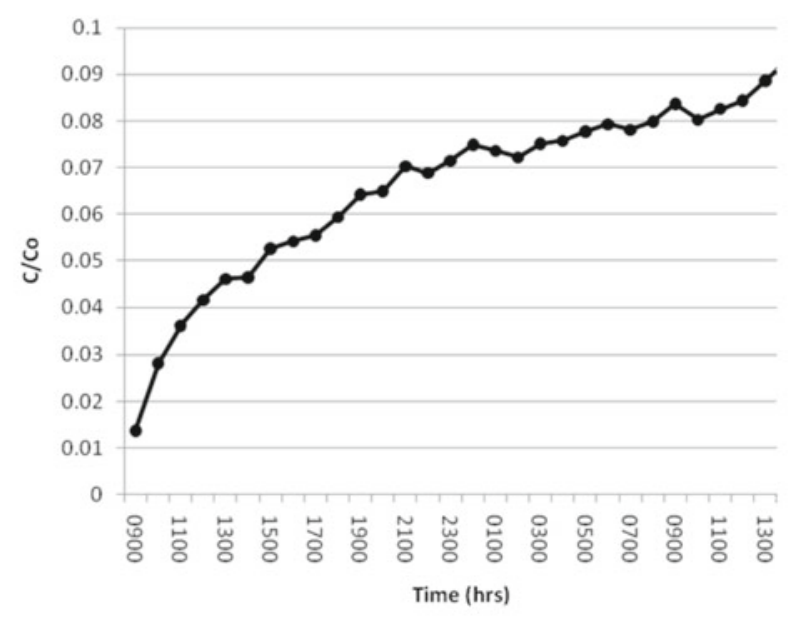

Figure 4. Sulfate breakthrough curve

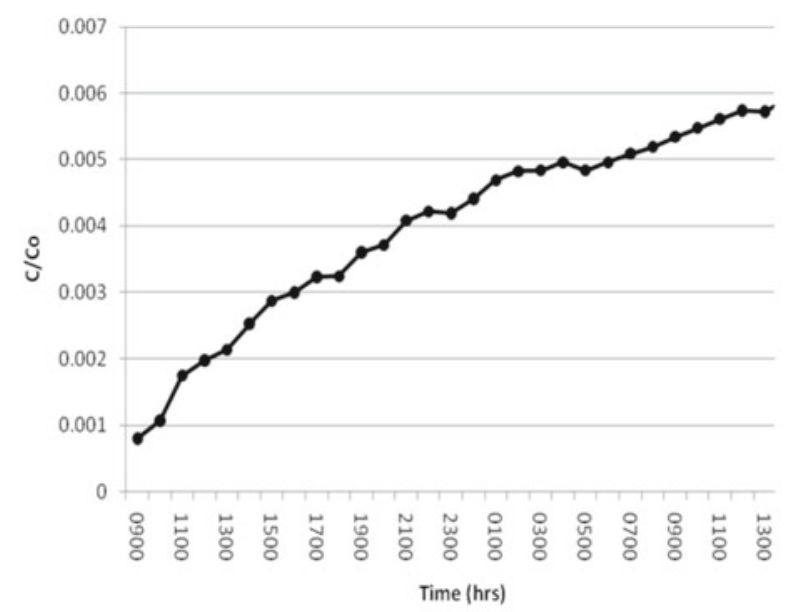

Figure 5. Silica breakthrough curve

early slippage of ions as sodium, potassium, sulfate and silica breakthrough. The run length of the train depends upon the silica leakage and due to its early leakage, the running time of the rain decreases.

Sodium leakage has a direct effect on silica leakage as sodium salt leaked from cation exchanger exchanges anion in the primary anion exchanger producing caustic soda. This caustic soda starts regenerating the exchanged silica at the top of the secondary anion exchanger. A small sodium leakage affects silica leakage very much.
Sodium leakage at the outlet of secondary anion exchanger contributes ton increase in conductivity and $\mathrm{pH}$ as shown in Figure 6-8.

Free mineral acidity (FMA) comprises sulfuric acid $\left(\mathrm{H}_{2} \mathrm{SO}_{4}\right)$, hydrochloric acid $(\mathrm{HCl})$ and Nitric acid $\left(\mathrm{HNO}_{3}\right)$ at the outlet of cation exchanger appears due to the exchange of cations of their respective salts. FMA decreases with the passage of time as shown in Figure 9 and there is a slight decreasing trend showing the ability of cation exchanger to exchange ion decreases with the passage of time. Primary anion exchanger removes strong acids from the decationized water and there is no slippage of FMA at the outlet although there is 5 ppm FMA maximum allowable outlet limit. This shows that the primary anion exchanger had the capacity to exchange more ions when the train was taken out of service.

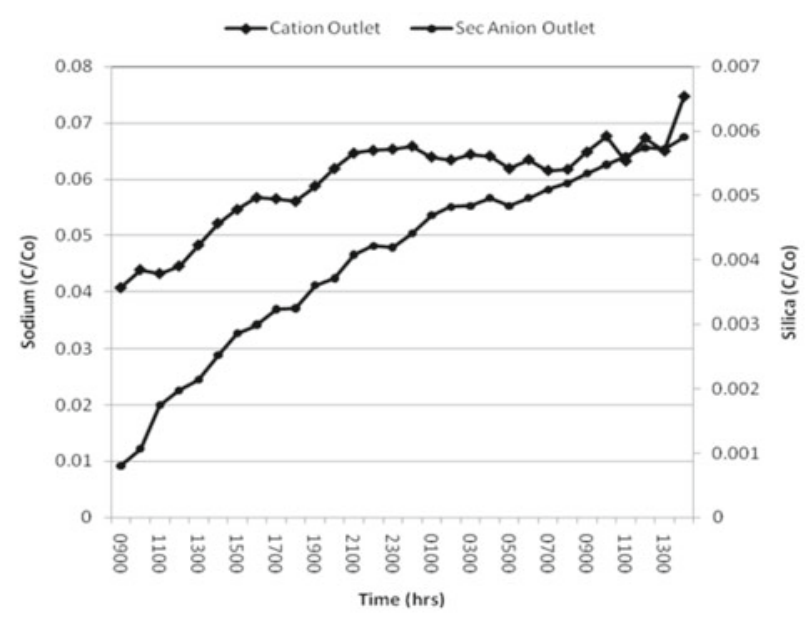

Figure 6. Effect of sodium on silica breakthrough

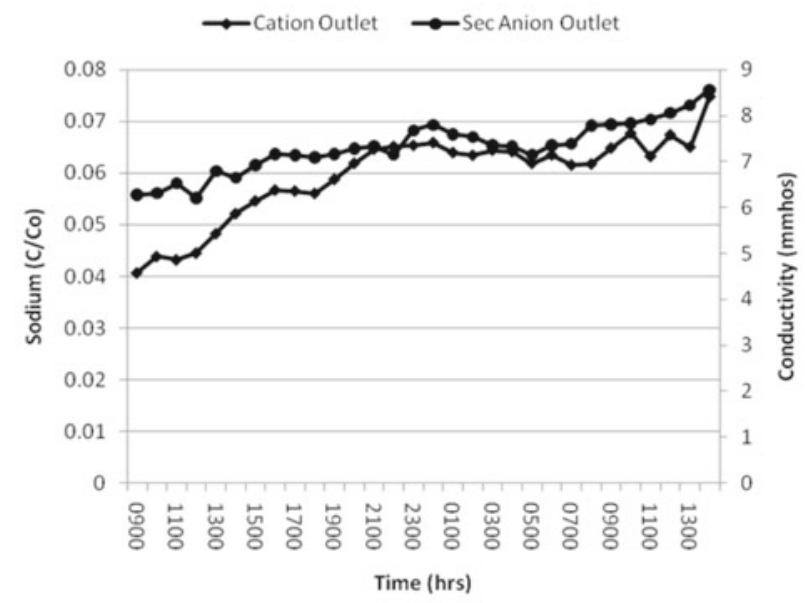

Figure 7. Effect of sodium on S-anion outlet conductivity

The $\mathrm{pH}$ of raw water at the inlet of cation exchanger remains nearly constant except at the end of the train it shows an increasing trend while at the outlet $\mathrm{pH}$ remains constant as in Figure 10. Conductivity at the inlet and outlet of cation exchanger demonstrates a decreasing trend. Conductivity at the inlet of train was higher than that of the outlet then it decreases further as shown in Figure 11.

The $\mathrm{pH}$ at the inlet of primary anion exchanger is nearly constant while it has a decreasing trend with the 


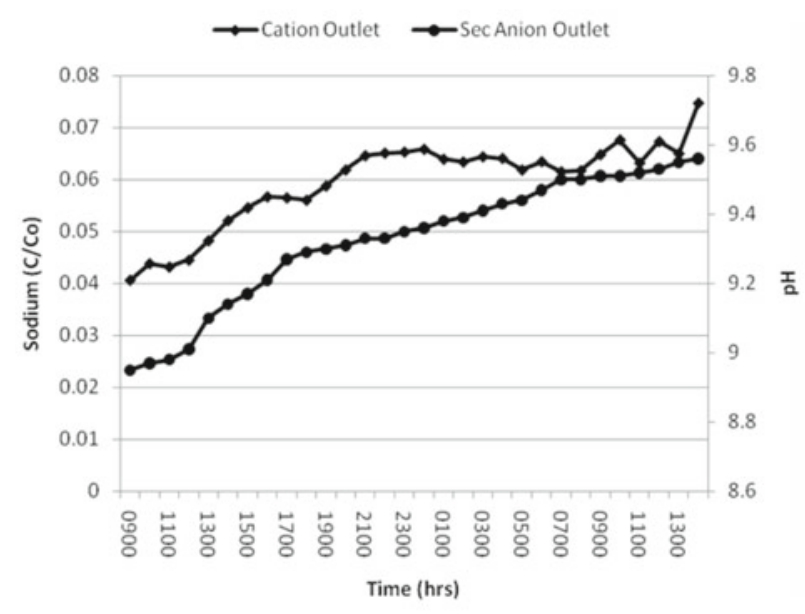

Figure 8. Effect of sodium on S-anion Outlet $\mathrm{pH}$

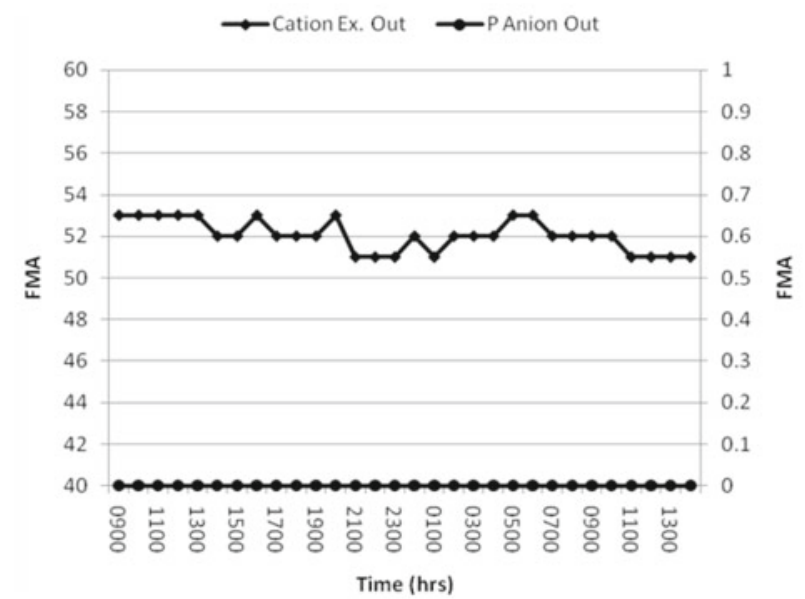

Figure 9. FMA at outlet of cation exchanger and P-anion exchanger outlet

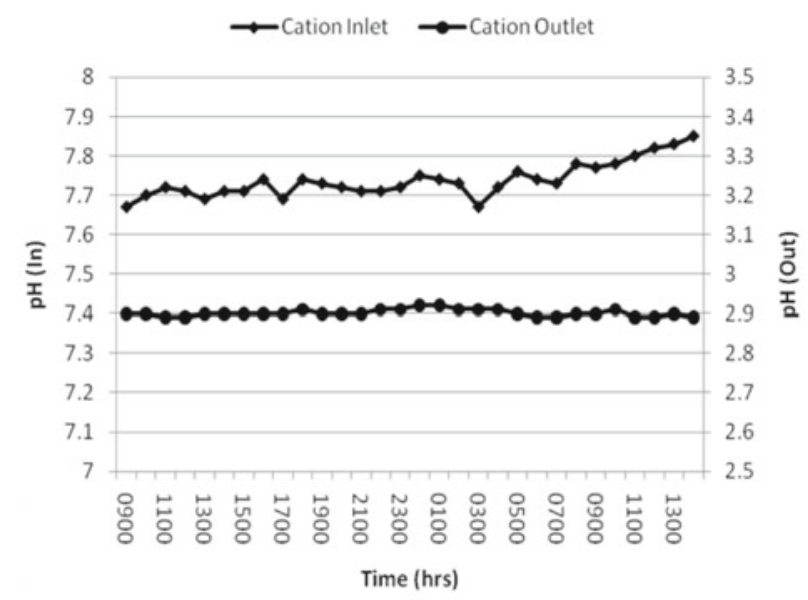

Figure 10. $\mathrm{pH}$ at Cation exchanger inlet and outlet

passage of time as in Figure 12. The inlet conductivity of the primary anion ( $\mathrm{p}$-anion) exchanger has slight but the outlet conductivity has a large increasing trend due to a decrease in the outlet $\mathrm{pH}$ as in Figure 13.

The inlet $\mathrm{pH}$ of the secondary anion (s-anion) exchanger decreases while the outlet $\mathrm{pH}$ increases with the passage of time as in Figure 14. The inlet conductivity of the secondary anion exchanger is lower than that of the outlet due to sodium. Because sodium salts exchange their negative parts in secondary anion exchanger that

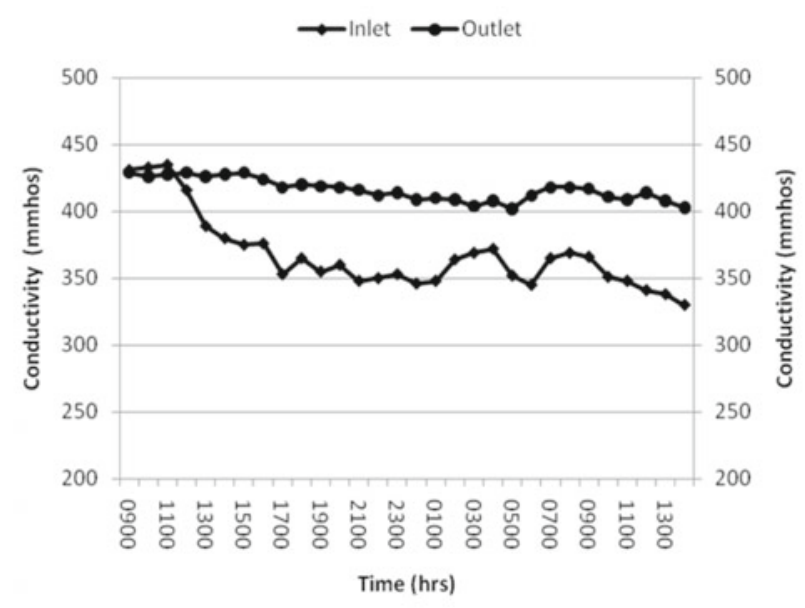

Figure 11. Conductivity at cation exchanger inlet and outlet

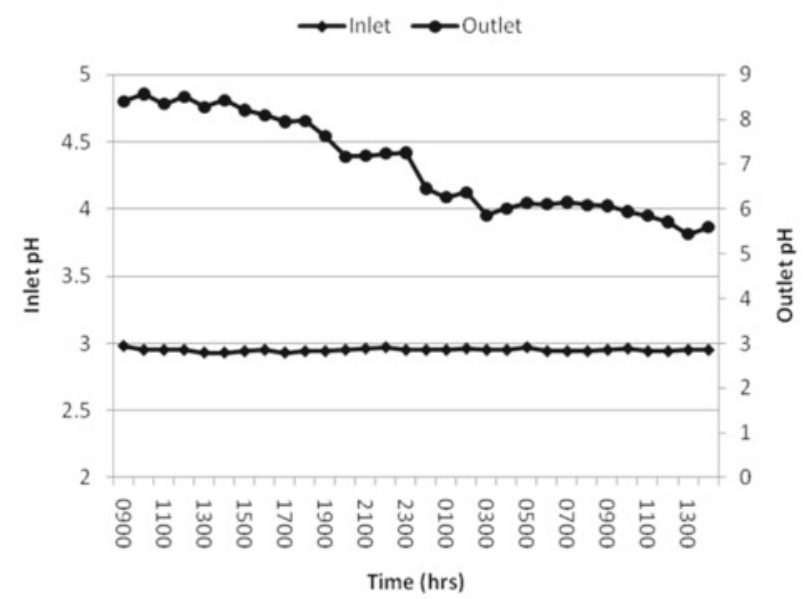

Figure 12. $\mathrm{pH}$ at $\mathrm{P}$-anion exchanger inlet and outlet

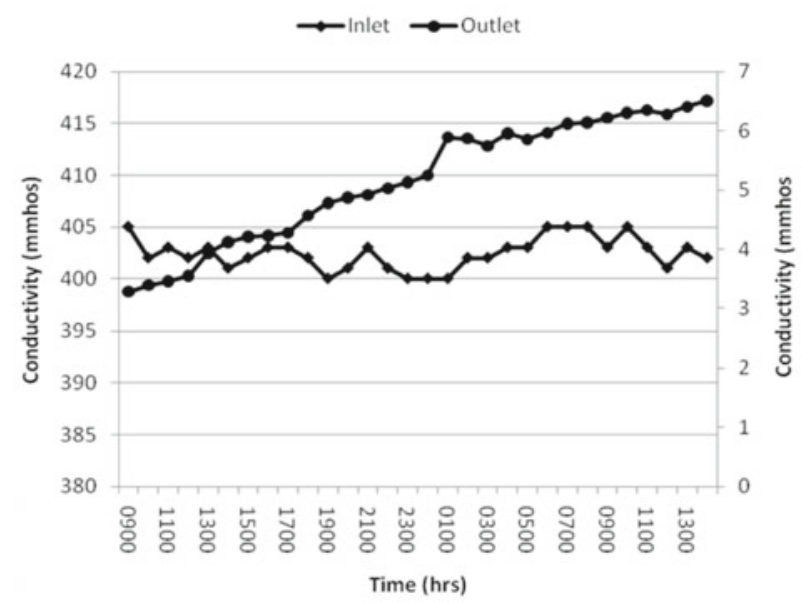

Figure 13. Conductivity at P-anion exchanger inlet \& outlet

produces $\mathrm{NaOH}$ that contributes to an increase in conductivity as shown in Figure 15.

Average water flow rate through train A was 1115.4 lit/ min. The volume of the water passed through the cation exchanger over 29 hours is 2,122,471 liters, through the primary anion exchanger is 2,040,706 liters and through the secondary anion exchanger is 1940,582 liters. The volume of the water passed through the cation and primary anion exchanger also includes the amount of water that was used to regenerate another train. 
Table 2. Capacity utilization of water treatment plant

\begin{tabular}{|c|c|c|c|c|c|c|c|c|c|}
\hline \multirow[t]{2}{*}{ 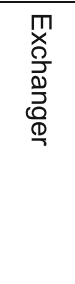 } & \multirow[t]{2}{*}{ 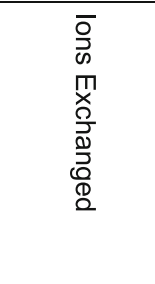 } & 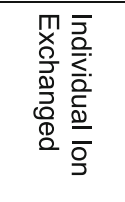 & 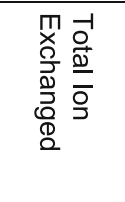 & 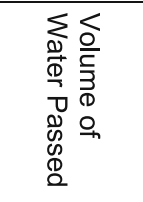 & 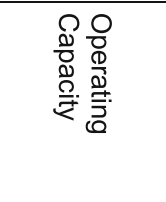 & 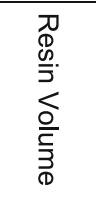 & 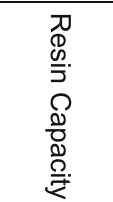 & 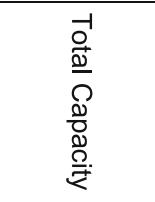 & 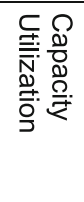 \\
\hline & & meq/liter & meq/liter & Liters & Equivalents & Liters & Eq/Liter & Equivalents & $\%$ age \\
\hline \multirow{4}{*}{ 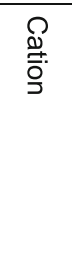 } & Calcium & 3.779 & \multirow{4}{*}{7.6042} & \multirow{4}{*}{$2,122,471$} & \multirow{4}{*}{16140} & \multirow{4}{*}{11327} & \multirow{4}{*}{2.1} & \multirow{4}{*}{23787} & \multirow{4}{*}{67.85} \\
\hline & Magnesium & 3.134 & & & & & & & \\
\hline & Sodium & 0.594 & & & & & & & \\
\hline & Potassium & 0.0972 & & & & & & & \\
\hline \multirow{2}{*}{ 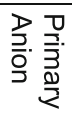 } & Chloride & 0.2812 & \multirow{2}{*}{1.1589} & \multirow{2}{*}{$2,040,706$} & \multirow{2}{*}{2365} & \multirow{2}{*}{4673} & \multirow{2}{*}{1.3} & \multirow{2}{*}{6075} & \multirow{2}{*}{38.93} \\
\hline & Sulfate & 0.8777 & & & & & & & \\
\hline \multirow{2}{*}{ 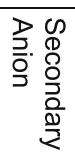 } & $\begin{array}{l}\text { Carbon } \\
\text { Dioxide }\end{array}$ & 0.4545 & \multirow{2}{*}{0.5985} & \multirow{2}{*}{$1,940,582$} & \multirow{2}{*}{1162} & \multirow{2}{*}{5324} & \multirow{2}{*}{1.3} & \multirow{2}{*}{6921} & \multirow{2}{*}{16.78} \\
\hline & Silica & 0.144 & & & & & & & \\
\hline
\end{tabular}

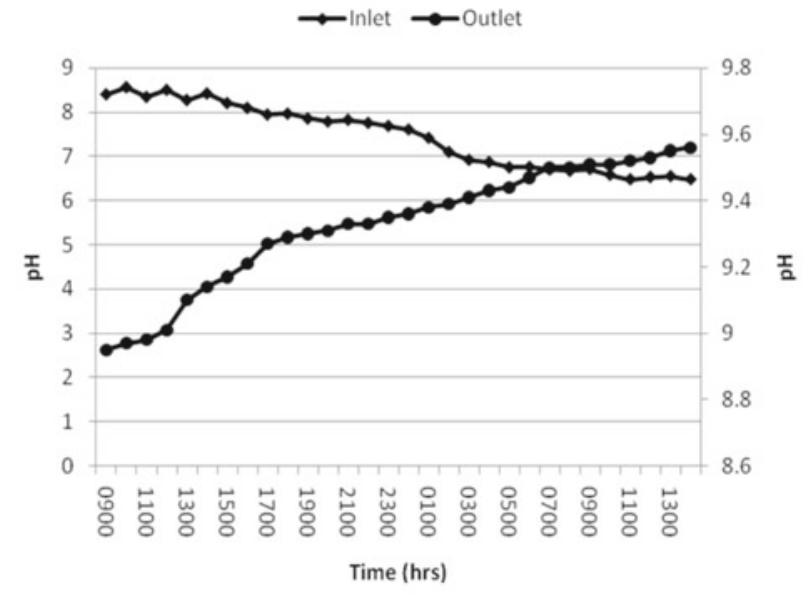

Figure 14. $\mathrm{pH}$ at $\mathrm{S}$-anion exchanger inlet and outlet

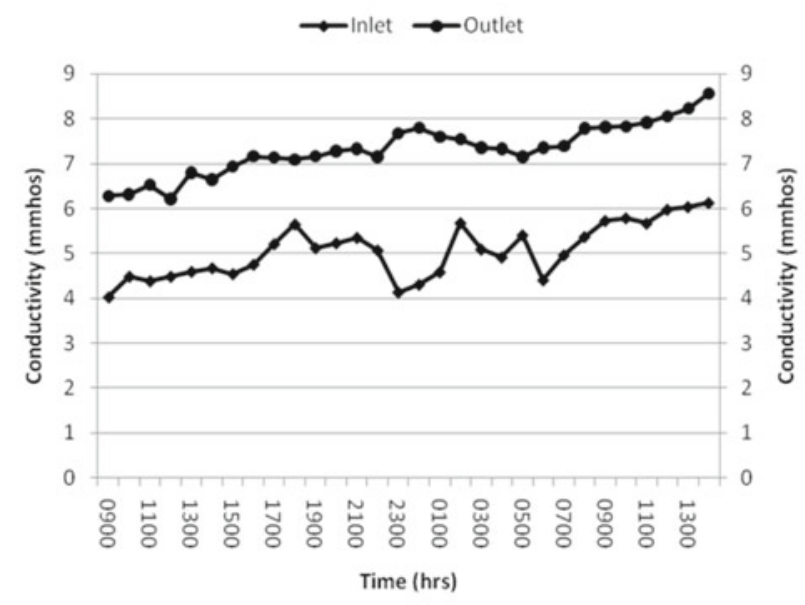

Figure 15. Conductivity at S-anion exchanger inlet and outlet

Table 2 describes the capacity utilization of ions exchangers of the water treatment plant. The capacities utilization of cation, primary anion and secondary anion exchangers are $67.85 \%, 38.93 \%$ and $16.78 \%$. Design

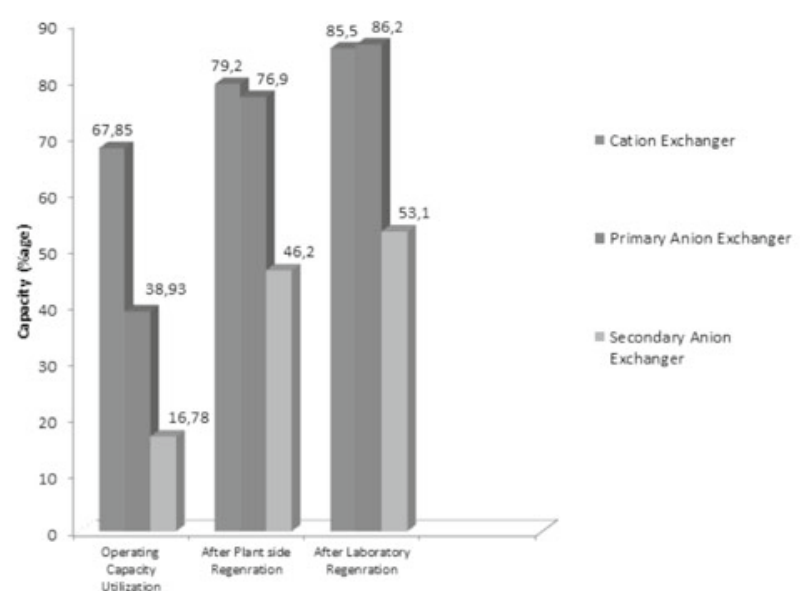

Figure 16. Capacity utilization of cation, primary anion and secondary anion exchangers'

operating column utilization of cation exchanger considered is usually $90 \%$ and that of anion exchangers is $85 \%$ in which the 5 percentage depreciation is due to silica slippage. The train is normally taken out of service when the concentration of silica reaches $0.050 \mathrm{mg} / \mathrm{lit}$. Due to early slippage of silica, the capacity of the secondary anion exchanger could not be fully utilized and due to this other exchangers could not be fully utilized. By increasing the capacity utilization of the secondary anion exchanger, the operating time can be increased.

The causes of the low capacity utilization of anion resin are the insufficient regenerant $(\mathrm{NaOH})$ dosage, the concurrent regeneration method, sodium leakage and organic fouling of the resin. If the insufficient regenerant dosage is used to regenerate the resin, then the bed capacity will not be fully available for the exchange process. This will cause early silica slippage. As discussed earlier, in the concurrent regeneration method, the lower portion of the resin bed cannot be fully regenerated, which results in early silica slippage. A small proportion 
of sodium slippage directly influences silica slippage as shown in Fig. 6. Organic contamination present in the surface water such as humic acid and fulvic acid etc exchange during the service cycle but cannot be fully removed during regeneration this results in low capacity available after regeneration.

To check the causes of lower capacity utilization, resin samples of cation and anion exchangers were collected after regeneration at the plant site. These samples were analyzed as such to check its available capacity after plant side regeneration. The available capacity of cation, primary anion and secondary anion exchangers after plant side regeneration are $79.2 \%, 76.9 \%$ and $46.2 \%$ as shown in figure 16. It shows that cation exchanger column utilization is $67.85 \%$ from $79.2 \%$ available capacity, primary anion exchanger column utilization is $38.93 \%$ and secondary anion exchanger column utilization is $16.78 \%$ from $46.2 \%$ available capacity. In secondary anion exchanger, column utilization $16.78 \%$ from $46.2 \%$ is due to the concurrent regeneration, the effect of sodium leakage on silica slippage.

To check the effect of regenerant dosage, these resin samples were further regenerated with excess amount of hydrochloric acid and caustic soda in laboratory and again their capacities were assessed. The available capacity of cation exchanger increases from $79.2 \%$ to $85.5 \%$, that of primary anion exchanger increases from $76.9 \%$ to $86.2 \%$ and that of secondary anion exchanger increases from $46.2 \%$ to $53.1 \%$ as shown in figure 16 . There is a small increase in available capacities of cation and anion resins after using the excess regenerant.

After regenerating with the excess amount of the regenerant, the maximum capacity available of the secondary anion exchanger is only $53.1 \%$. As the strong base anion resin is being used in secondary anion exchanger that is more susceptible to organic fouling. This might be the cause of its lower available capacity and another cause may be the physical degradation of resin.

\section{CONCLUSIONS}

Calcium, magnesium and chloride leakage was not observed throughout the operating time of the train while the breakthrough curves of sodium, potassium, sulfate and silica show their early leakage that affects the ion exchangers operation. Sodium leakage contributes to early silica leakage and reduced the operating time. The secondary anion exchanger using only $16.8 \%$ capacity from $46.2 \%$ available capacity, primary anion exchanger is using $38.9 \%$ from $76.9 \%$ available capacity and cation exchanger is using $67.9 \%$ from $79.2 \%$ available capacity. The available capacities of cation, primary anion and secondary anion exchanger increase from $79.2 \%$ to $85.5 \%, 76.9 \%$ to $86.2 \%$ and $46.2 \%$ to $53.1 \%$ after regenerating with the excess regenerant. The secondary anion exchanger available capacity after the excess regenerant dosage is only $53.1 \%$, this may be due to the organic fouling and physical and chemical deterioration. It is recommended to check the causes of lower available capacities of resins based on detailed analyses including organic and iron fouling levels, \%age moisture contents, capacity dry basis, total capacity, density, beads broken, cracked, perfect and ash percentages.

\section{ACKNOWLEDGEMENT}

The authors are thankful to the Dawood Hercules Chemicals Limited, Lahore - Pakistan and Chemical Engineering Department University of Engineering and Technology Lahore for providing the facilities for carrying out this research.

\section{LITERATURE CITED}

1. Noh, B.I., Lee, C.W., Yoon, T.K., Moon, B.H., Lee, G.C. \& Shin, C.H.(1999). Parametric Studies on the Performance of Mixed-Bed Ion Exchange at Ultralow Concentration. Korean J. Chem. Eng. 16(6), 737-744. DOI: 10.1007/BF02698345.

2. Kunin, R. \& McGarvey, F.X. (1964). Ion Exchange, Ind. Eng. Chem. 56 (10), 53-56, DOI: 10.1021/ie50658a009.

3. Kunin, R. \& Gustafson, R.L. (1967). Ion Exchange, Ind. Eng. Chem. 59(11), 95-100, DOI: 10.1021/ie50695a013.

4. Clifford, D.A. (1996). Ion Exchange and Inorganic Adsorption. In Letterman R.D.(5 ${ }^{\text {th }}$ Eds.). Water Quality and Treatment - A Handbook of Community Water Supplies (pp 9.1-9.91). McGraw Hill.

5. Chowdiah, V. \& Foutch, G.L.,(1995). A Kinetic Model for Cationic-Exchange-Resin Regeneration. Ind. Eng. Chem. 34(11), 4040-4048. DOI: 10.1021/ie00038a045.

6. Beyer, W.A. \& James, D.B. (1966). Independence of Performance of Ion-Exchange Column on Its Shape, Ind. Eng. Chem. 5(3), 433-434. DOI: 10.1021/1160019a024.

7. Clifford, D. (1982). Multicomponent ion-exchange calculations for selected ion separations, Ind. Eng. Chem. Fundamen. 21(2), 141-153. DOI: 10.1021/1100006a008.

8. Ahmed, R.A, Ahmad, A., Omar, M. \& Kadir, A. (2008). Studies on Breakthrough Time of Strong Cation Exchange Resin in a Water Treatment Plant, 28-30 May 2008 (pp 880-885), penang, Malaysia, ICERT,

9. Vermeulen, T. \& Huffman, E.H. (1953). Ion Exchange Column Performance Hydrogen Cycle Rates in Nonaqueous Solvents, Ind. Eng. Chem. 45(8), 1658-1664. DOI: 10.1021/ ie $50524 \mathrm{a} 024$.

10. Frisch, N. \& Kunin, R. (1957). Long-Term Operating Characteristics of Anion Exchange Resins, Ind. Eng. Chem. 49(9), 1365-1372. DOI: 10.1021/ie50573a028.

11. Helfferich, F. (1962). Ion Exchnage, Mc Graw Hill, New Ýork, 424.

12. Mindick, M. (1955). Capacity and Leakage of Ion Exchange Columns, Ind. Eng. Chem. 47(I), 96-101 DOI: 10.1021/ie50541a035.

13. Ning, R.Y.(2002). Discussion of silica speciation, fouling, control and maximum reduction, Desalination. 151, 67-73 Doi.10.1016/S0011916402009736.

14. Ali, M.B.S., Hamrounl, B., Bouguecha, S. \& Dhahbi, M.(2004). Silica removal using ion-exchange resins, Desalination. 167,273-279,doi /10.1016/j.desal.2004.06.136. 